\title{
Kinetic and temporospatial parameters in male and female cats walking over a pressure sensing walkway
}

\author{
Mirela R Verdugo ${ }^{1}$, Sheila C Rahal ${ }^{1 *}$, Felipe S Agostinho ${ }^{1}$, Verônica M Govoni ${ }^{1}$, Maria J Mamprim² \\ and Frederico OB Monteiro ${ }^{3}$
}

\begin{abstract}
Background: Several factors may influence kinetic data measurements, including body conformation and body mass. In addition, gender differences in gait pattern have been observed in healthy humans. Therefore, the aim of this study was to compare the kinetic and temporospatial parameters in clinically healthy male and female cats using a pressure-sensitive walkway. Eighteen crossbreed adult cats were divided into two groups: G1 had ten male cats (nine neutered) aged from 1 to 4 years and body mass 3.1-6.8 kg; G2 had eight spayed female cats, aged from 1 to 6 years and body mass $3.3-4.75 \mathrm{~kg}$. The data from the first five valid trials were collected for each cat. A trial was considered valid if the cat maintained a velocity between $0.54-0.74 \mathrm{~m} / \mathrm{s}$ and acceleration from -0.20 to $0.20 \mathrm{~m} / \mathrm{s}^{2}$. The peak vertical force (PVF), vertical impulse (VI), gait cycle time, stance time, swing time, stride length, and percentage body weight distribution among the four limbs were determined. In addition, the lengths of each forelimb and each hind limb were measured using a tape with the animal standing.

Results: No significant differences were observed in each group in either the forelimbs or the hind limbs or between the left and right sides for any of the variables. For both groups, the PVF (\%BW), the VI, and the percentage body weight distribution were higher at the forelimbs than the hind limbs. The stride length was larger for males; however, the other kinetic and temporospatial variables did not show any statistically significant differences between the groups. The lengths of the forelimbs and hind limbs were larger in the male cats. There was a significant moderate positive correlation between the stride length and the length of the limbs.
\end{abstract}

Conclusions: In conclusion, the only difference observed between male and female cats was the stride length, and this was due to the greater body size of male cats. This difference did not affect other temporospatial or kinetics variables.

\section{Background}

In small animals, instrumented gait analysis has generally been performed more frequently in dogs; kinetic and kinematic methods or a combination of both methods have been used [1-4]. Consequently, knowledge of the ground reaction forces and joint angles as well as the temporospatial parameters has provided a better understanding of gait biomechanics and characteristics and has allowed a better clinical application of the gait analysis $[3,4]$, although the cost and complexity of these

\footnotetext{
* Correspondence: sheilacr@fmvz.unesp.br

${ }^{1}$ Department of Veterinary Surgery and Anesthesiology, School of Veterinary Medicine and Animal Science - Univ Estadual Paulista (UNESP), Botucatu, SP, Brazil

Full list of author information is available at the end of the article
}

systems restricts gait analysis to laboratories [5]. Gait examination in cats has been accomplished most commonly by visual methods. The exam is performed in closed rooms or by evaluating videotape that is recorded in the home environment, as these animals seldom agree to walk on a leash and refuse to move freely in an unfamiliar environment [6]. However, objective analysis can be done in cooperative or trained cats [5,7-12].

Kinetic analysis provides information about the forces produced during the gait cycle; the ground reaction force and the joint reaction force are most studied $[1,13,14]$. The measurement of ground-reaction forces is important to predict, describe and assess gait disabilities and functional outcome $[4,13,14]$. In small animals the ground-reaction forces have been more frequently

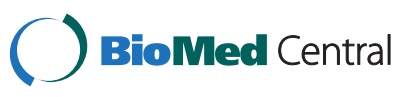


measured by force platform; however, the use of pressure sensing walkway has increased, as this system allows the recording of multiple foot strike data in a single passage and may be used with small breed dogs and cats [2-4,7-9,11,15-19]. Another advantage of pressure sensing walkway technology is that it allows to gather data from left and right limbs in one pass over the measuring area, resulting in easy calculation of (a)symmetry ratios and symmetry index $[18,19]$. In addition, pressure plate equipment is not restricted to high-tech gait laboratories, unlike 3D kinematics and force plate analysis $[19,20]$.

There are differences between the absolute force values recorded by the force platforms and those collected by pressure sensing systems, which are generally lower $[2,15,16,20,21]$. Several reasons have been proposed to explain the differences such as calibration techniques, type of sensors, and sampling frequency $[15,21]$. Therefore, the results obtained by different systems are not interchangeable $[21,22]$. Peak vertical force (PVF) and vertical impulse (VI) are the most commonly parameters used to analyse normal and abnormal gait in small animals [2-4,12,23,24], and PVF is the only force measured by pressure sensing walkway $[2,7-9,15,16,25]$. In addition to ground reaction forces, temporal and distance parameters of gait such as stride length, stride time, stance time, percentage of stance, swing time, and velocity may also be evaluated $[17,18,26]$.

Several factors may influence kinetic data measurements $[1,4,23]$, including body conformation and body mass $[20,23,27,28]$. In addition, gender differences in gait pattern have been observed in healthy humans [29]. Therefore, the aim of this study was to compare the kinetic and temporospatial parameters in clinically healthy male and female cats. The hypothesis was that these parameters may have differences that are associated with sex or body conformation.

\section{Methods}

This study was approved by the Ethics Committee of the School of Veterinary Medicine and Animal Science UNESP Botucatu ( $\mathrm{n}^{\circ}$ 175/2011-CEUA). Permission to use the cats in the study was obtained from the owners.

Thirty clinically healthy cats recruited from clientowned or shelter-owned were used. The cats were judged to be healthy from complete physical, and orthopaedic examinations based on described by Voss and Steffen [6]. Although the cats did not have any signs of orthopaedic disease, digital radiographs only of the hip joints and stifle joints were obtained to complement clinical examination. One experienced radiologist reviewed the radiographs. Before the data collection, the cats were acclimatised to the room and stimulated to walk across the walkway for 1 hour or more. Each cat was weighed on the same electronic scale immediately before data collection.

\section{Data collection}

The kinetic and temporospatial parameters of gait were measured with a $1951 \mathrm{~mm} \times 447 \mathrm{~mm}$ pressure-sensitive walkway (Walkway High Resolution HRV4; Tekscan, South Boston, Massachusetts, USA) containing 33,408 pressure-sensitive cells. The sensors of the pressuresensing walkway were equilibrated and calibrated using a phantom as reported previously [26] and according to the manufacturer's specifications. During each trial, the cats were stimulated to walk in a straight line over the pressure-sensitive walkway; toys, food, and occasionally the presence of the owner were necessary to accomplish this task. In general, the stimulus was done with the materials positioned at the opposite end of the walkway. Boards measuring $2 \times 0.8 \mathrm{~m}$ were placed on both sides of the walkway when deemed necessary.

For each animal, an average of 20 trials was obtained. The data from the first five valid trials were selected for each cat and analysed using designated software (Walkway 7.0; Tekscan, Boston, USA). A trial was considered valid if the cat walked at velocity within a previously determined range $(0.54-0.74 \mathrm{~m} / \mathrm{s})$ and acceleration $\left(-0.20\right.$ to $\left.0.20 \mathrm{~m} / \mathrm{s}^{2}\right)$ parameters and if the 4 limbs had contacted with the surface of the walkway during each walk cycle.

For each limb, the gait cycle time (s), stance time (s) swing time $(\mathrm{s})$ and stride length $(\mathrm{m})$ were the determined temporospatial parameters. The stance time percentage was calculated as follows: (stance time/gait cycle time) $\times 100$. The swing time percentage was calculated as follows: (swing time/gait cycle time) $\times 100$. The stride corresponded to the distance between two consecutive ground contacts of the same limb.

The PVF and the VI were the kinetic parameters determined. The PVF and VI were normalised to the cat's body weight and represented as a percentage of body weight, $\% \mathrm{BW}$ and \%BW"t, respectively. The percentage of body distribution among the four limbs was calculated as follows: (PVF of the limb/total PVF of the 4 limbs) $\times 100$.

The duty factor in the hind limbs was calculated by dividing stance time by gait cycle time.

\section{Limb lengths}

With the animal standing, the lengths of each forelimb and each hind limb were measured $(\mathrm{cm})$, respectively, by the distance from the ground to the dorsal scapular rim and from the ground to the iliac crest using a generic plastic tape (metric).

\section{Symmetry ratio and maximum percentage of asymmetry}

Since the side of asymmetry can vary, the symmetry ratio was calculated by dividing the highest value by the 
lowest value of each variable [30]. A mean (SD) of the 5 measurements of every animal was used. The maximum percentage of asymmetry was calculated by the formula: (Symmetry index -1$) \times 100$.

\section{Statistical method}

To compare the temporospatial parameters and the kinetic data was used general linear model with sides (left and right) and sex (male and female) as fixed factors. An independent sample T-test was used to compare lengths of the forelimbs and hind limbs between groups. The values were expressed as the means \pm standard deviation, and the coefficients of variation $(\mathrm{CV})$ were calculated with the comparison data between the groups. Differences were considered significant at $P<0.05$.

The symmetry index was expressed as mean \pm standard deviation. The maximum percentage of asymmetry was determined by the upper percentage of the confidence interval calculated at $95 \%$ including all cats.

Pearson's correlation coefficients $(r)$ were used to evaluate the linear relationships between the limb lengths and the temporospatial parameters and kinetic parameters. The correlations were deemed significant at the $5 \%$ probability level.

\section{Results}

All 30 animals were in the inclusion criteria of healthy animals. However, twelve cats were excluded because were not able to walk according to determined velocity, or in straight line without turn the head or without stop. The greatest difficulty was having the cat walk the course in a straight line at a constant velocity without any distractions. Only seven cats walked without use of boards.

From the 18 cats included in the study 16 were owned by clients, and two were shelter-owned. These cats were divided into two groups: G1 had 10 male crossbreed cats (of which nine were neutered) aged from 1 to 4 years and body mass 3.1-6.8 $\mathrm{kg}$ (mean $4.39 \mathrm{~kg} \pm 1.14 \mathrm{SD}$ ); G2 had eight spayed female crossbreed cats aged from 1 to 6 years and body mass $3.3-4.75 \mathrm{~kg}$ (mean $3.82 \mathrm{~kg} \pm 0.50$ $\mathrm{SD})$. The cats have been neutered/spayed from 11 months to 5 years. There were no body mass differences between the groups $(P=0.205)$.

No radiographic lesions were observed in the hip or stifle joints. The exception was a small meniscal mineralisation observed in both stifle joints in one cat of the G2, but without other clinical signs.

No significant differences were found between the kinetic data and the temporospatial parameters of the left and right forelimbs or the left or right hind limbs (Tables 1 and 2) in either group. In both groups, the PVF (\%BW), $\mathrm{VI}$, and the percentage of body weight distribution were higher at the forelimbs than the hind limbs $(P<0.001)$. The mean \pm SD velocities were $0.63 \pm 0.06 \mathrm{~m} / \mathrm{s}$ and $0.61 \pm$ $0.04 \mathrm{~m} / \mathrm{s}$ in the male and female cats, respectively $(P=0.47)$.

The stride length was larger for male cats; however, the other kinetic and temporospatial variables did not show any significant difference between the groups (Table 3).

Significant differences were found between the forelimbs and hind limbs for both G1 and G2 in the swing time $(P=0.001, P<0.001)$, swing percentage $(P<0.001$, $P=0.011)$, stance percentage $(P<0.001, P=0.002)$, PVF $(P<0.001, P<0.001)$, VI $(P<0.001, P<0.001)$, and body distribution percentage $(P<0.001, P<0.001)$.

The symmetry rate and the maximum percentage of asymmetry of the kinetic and temporospatial variables are described in Table 4 . The hind limb duty factors had a mean of 0.55 for the male cats and 0.54 for the female cats. There were differences in the lengths of the forelimbs and the hind limbs, which were both larger in the male cats (Table 5). There was a significant moderate positive correlation between the stride length and the length of the limbs (Table 6).

Table 1 Comparison of the temporospatial parameters and the kinetic data between the right and left sides of the forelimbs of male and female cats

\begin{tabular}{|c|c|c|c|c|c|c|}
\hline & \multicolumn{2}{|c|}{ Male } & \multicolumn{2}{|c|}{ Female } & \multirow[b]{3}{*}{$P$ value } & \multirow[b]{3}{*}{ Power } \\
\hline & Right & Left & Right & Left & & \\
\hline & $\overline{\text { Mean } \pm \text { SD }}$ & $\overline{\text { Mean } \pm \text { SD }}$ & Mean \pm SD & Mean \pm SD & & \\
\hline Stance Time (s) & $0.48 \pm 0.08$ & $0.48 \pm 0.07$ & $0.46 \pm 0.06$ & $0.45 \pm 0.07$ & 0.850 & 0.054 \\
\hline Swing Time (s) & $0.34 \pm 0.04$ & $0.34 \pm 0.04$ & $0.33 \pm 0.03$ & $0.33 \pm 0.03$ & 0.969 & 0.050 \\
\hline Gait cycle time (s) & $0.80 \pm 0.10$ & $0.79 \pm 0.10$ & $0.76 \pm 0.10$ & $0.76 \pm 0.09$ & 0.962 & 0.050 \\
\hline Stride Length $(\mathrm{m})$ & $0.49 \pm 0.02$ & $0.49 \pm 0.03$ & $0.45 \pm 0.01$ & $0.45 \pm 0.01$ & 0.724 & 0.064 \\
\hline$\%$ of Stance & $59.30 \pm 3.61$ & $59.72 \pm 4.17$ & $60.24 \pm 2.78$ & $59.12 \pm 4.27$ & 0.787 & 0.058 \\
\hline$\%$ of Swing & $43.16 \pm 2.61$ & $42.41 \pm 1.92$ & $43.07 \pm 4.11$ & $43.62 \pm 4.49$ & 0.936 & 0.051 \\
\hline PVF (\%BW) & $54.54 \pm 5.99$ & $55.37 \pm 4.99$ & $55.15 \pm 5.66$ & $54.59 \pm 7.83$ & 0.742 & 0.062 \\
\hline $\mathrm{VI}\left(\% \mathrm{BW}^{*} \mathrm{~s}\right)$ & $18.08 \pm 3.56$ & $18.41 \pm 2.78$ & $18.36 \pm 3.36$ & $17.56 \pm 4.33$ & 0.428 & 0.122 \\
\hline$\%$ of Body Distribution & $28.25 \pm 1.39$ & $28.75 \pm 1.69$ & $29.15 \pm 0.99$ & $28.31 \pm 1.10$ & 0.844 & 0.054 \\
\hline
\end{tabular}


Table 2 Comparison of the temporospatial parameters and the kinetic data between the right- and left- side hind limbs of male and female cats

\begin{tabular}{|c|c|c|c|c|c|c|}
\hline & \multicolumn{2}{|c|}{ Male } & \multicolumn{2}{|c|}{ Female } & \multirow[b]{3}{*}{$P$ value } & \multirow[b]{3}{*}{ Power } \\
\hline & Right & Left & Right & Left & & \\
\hline & $\overline{M e a n} \pm$ SD & $\overline{M e a n} \pm$ SD & $\overline{M e a n} \pm$ SD & $\overline{M e a n} \pm$ SD & & \\
\hline Stance Time (s) & $0.46 \pm 0.07$ & $0.46 \pm 0.09$ & $0.45 \pm 0.06$ & $0.44 \pm 0.06$ & 0.859 & 0.053 \\
\hline Swing Time (s) & $0.39 \pm 0.05$ & $0.41 \pm 0.08$ & $0.38 \pm 0.04$ & $0.40 \pm 0.05$ & 0.357 & 0.148 \\
\hline Gait cycle time (s) & $0.83 \pm 0.11$ & $0.85 \pm 0.15$ & $0.81 \pm 0.09$ & $0.82 \pm 0.08$ & 0.778 & 0.059 \\
\hline Stride Length $(\mathrm{m})$ & $0.49 \pm 0.02$ & $0.49 \pm 0.02$ & $0.45 \pm 0.01$ & $0.44 \pm 0.02$ & 0.711 & 0.065 \\
\hline$\%$ of Stance & $55.26 \pm 3.85$ & $54.47 \pm 2.88$ & $55.67 \pm 4.98$ & $53.38 \pm 5.66$ & 0.301 & 0.175 \\
\hline$\%$ of Swing & $47.22 \pm 3.39$ & $48.25 \pm 1.95$ & $47.83 \pm 6.66$ & $49.59 \pm 7.17$ & 0.415 & 0.126 \\
\hline PVF (\%BW) & $42.05 \pm 7.03$ & $41.28 \pm 6.19$ & $40.97 \pm 5.30$ & $40.21 \pm 5.45$ & 0.711 & 0.065 \\
\hline $\mathrm{VI}\left(\% \mathrm{BW}^{*} \mathrm{~s}\right)$ & $13.36 \pm 2.63$ & $13.10 \pm 2.60$ & $13.38 \pm 3.04$ & $12.77 \pm 3.21$ & 0.360 & 0.147 \\
\hline$\%$ of Body Distribution & $21.67 \pm 1.56$ & $21.31 \pm 1.42$ & $21.28 \pm 1.00$ & $20.86 \pm 0.71$ & 0.656 & 0.072 \\
\hline
\end{tabular}

\section{Discussion}

The ground reaction force measurements may be affected by several factors; therefore, velocity conditions must be controlled and a consistent gait pattern is necessary [1,23]. Cat behavior is challenging when performing gait analysis $[6,11]$. In the present study, only 18 of 30 cats could be used in the gait analysis, despite several types of stimuli. In another study, 15 of 23 cats proved satisfactory for gait analysis [9].

In the present study, the gait velocity varied from 0.54 to $0.74 \mathrm{~m} / \mathrm{s}$ with no difference between the groups. This velocity was based on walking, as the hind limb duty factors were 0.55 and 0.54 for male and female cats, respectively. When the duty factor or the fraction of cycle time that the limb is on the ground is $>0.5$, the gait is considered walking for quadrupeds; $<0.5$ is suggestive of running or trotting [31].

Other studies that have used healthy cats walking on a pressure-sensitive walkway have reported velocities from
0.37 to $0.85 \mathrm{~m} / \mathrm{s}(0.6 \mathrm{~m} / \mathrm{s}$ mean $)$ [9] or mean values of $0.69 \pm 0.029 \mathrm{~m} / \mathrm{s}$ [9] and $0.67 \pm 0.22 \mathrm{~m} / \mathrm{s}$ [11]. The velocity influences the ground reaction forces and the stance time $[1,23]$. If the range is too large, it is impossible to conclude whether the differences are related to abnormal gait or velocity variations [23]. In cats, the maximum variation of the velocity is undefined.

The stance time and stance time percentage were greater than the swing time and swing time percentage for both the forelimbs and the hind limbs, with no difference between the males and the females. This is consistent with walking when the stance phase is longer than the swing phase and is confirmed by the duty factor. The same result was observed in dogs walking on a pressuresensitive walkway [18]. In addition, the stance duration decreases with increased velocity in a manner that is similar to the cycle duration in quadrupeds within a gait [31].

However, the stance time and gait cycle time were statistically similar between the forelimbs and the hind

Table 3 Comparison of the temporospatial parameters and the kinetic data between the forelimbs and hind limbs of male and female cats

\begin{tabular}{|c|c|c|c|c|c|c|c|c|c|c|c|c|}
\hline & \multicolumn{6}{|c|}{ Forelimb } & \multicolumn{6}{|c|}{ Hind limb } \\
\hline & \multicolumn{2}{|l|}{ Male } & \multicolumn{2}{|c|}{ Female } & \multirow[b]{2}{*}{$P$ value } & \multirow[b]{2}{*}{ Power } & \multicolumn{2}{|l|}{ Male } & \multicolumn{2}{|c|}{ Female } & \multirow[b]{2}{*}{$P$ value } & \multirow[b]{2}{*}{ Powe } \\
\hline & Mean \pm SD & $\mathrm{CV}$ & Mean \pm SD & CV & & & Mean \pm SD & $\mathrm{CV}$ & Mean \pm SD & $\mathrm{CV}$ & & \\
\hline Stance Time (s) & $0.48 \pm 0.07$ & 14.68 & $0.46 \pm 0.07$ & 15.32 & 0.453 & 0.114 & $0.46 \pm 0.08$ & 17.28 & $0.44 \pm 0.06$ & 13.19 & 0.491 & 0.104 \\
\hline Swing Time (s) & $0.34 \pm 0.04$ & 11.70 & $0.33 \pm 0.03$ & 9.12 & 0.231 & 0.220 & $0.40 \pm 0.06$ & 14.96 & $0.39 \pm 0.04$ & 10.13 & 0.770 & 0.059 \\
\hline Stride Time (s) & $0.80 \pm 0.09$ & 11.25 & $0.76 \pm 0.10$ & 13.07 & 0.319 & 0.166 & $0.84 \pm 0.13$ & 15.42 & $0.82 \pm 0.08$ & 9.80 & 0.532 & 0.094 \\
\hline Stride Length $(\mathrm{m})$ & $0.49 \pm 0.02 \mathrm{a}$ & 4.08 & $0.45 \pm 0.02 b$ & 4.45 & $<0.001$ & 0.996 & $0.49 \pm 0.02 a$ & 4.08 & $0.44 \pm 0.02 b$ & 4.49 & $<0.001$ & 1.000 \\
\hline$\%$ of Stance & $59.51 \pm 3.08$ & 5.18 & $59.68 \pm 3.53$ & 5.91 & 0.896 & 0.052 & $54.87 \pm 3.34$ & 6.09 & $54.53 \pm 5.28$ & 9.68 & 0.818 & 0.056 \\
\hline$\%$ of Swing & $42.78 \pm 2.26$ & 5.28 & $43.35 \pm 4.17$ & 9.62 & 0.619 & 0.078 & $47.74 \pm 2.75$ & 5.76 & $48.71 \pm 6.75$ & 13.86 & 0.569 & 0.086 \\
\hline PVF (\%BW) & $54.95 \pm 5.38$ & 9.79 & $55.75 \pm 7.66$ & 13.74 & 0.724 & 0.064 & $41.66 \pm 6.46$ & 15.51 & $40.59 \pm 5.21$ & 12.83 & 0.603 & 0.080 \\
\hline $\mathrm{VI}\left(\% \mathrm{BW}^{*} \mathrm{~s}\right)$ & $18.24 \pm 3.11$ & 17.05 & $17.96 \pm 3.77$ & 20.99 & 0.355 & 0.149 & $13.23 \pm 2.55$ & 19.27 & $13.07 \pm 3.04$ & 23.26 & 0.329 & 0.161 \\
\hline$\%$ of Body Distribution & $28.50 \pm 1.53$ & 5.37 & $28.92 \pm 1.13$ & 3.91 & 0.809 & 0.056 & $21.49 \pm 1.47$ & 6.84 & $21.07 \pm 0.87$ & 4.13 & 0.872 & 0.053 \\
\hline
\end{tabular}

The values that are followed by different letters along each horizontal row are significantly different. 


\begin{tabular}{|c|c|c|c|c|}
\hline \multirow[t]{2}{*}{ Variables } & \multicolumn{2}{|c|}{$\begin{array}{l}\text { Symmetry ratio } \\
\text { left/right side }\end{array}$} & \multicolumn{2}{|c|}{$\begin{array}{l}\text { Maximum } \\
\text { percentage of } \\
\text { asymmetry }\end{array}$} \\
\hline & Forelimb & Hind $\operatorname{limb}$ & Forelimb & Hind limb \\
\hline Stance Time (s) & $1.05 \pm 0.05$ & $1.05 \pm 0.04$ & $8.5 \%$ & $7.6 \%$ \\
\hline Swing Time (s) & $1.06 \pm 0.06$ & $1.08 \pm 0.06$ & $6.9 \%$ & $11.9 \%$ \\
\hline Gait cycle time (s) & $1.04 \pm 0.03$ & $1.03 \pm 0.03$ & $6.1 \%$ & $5.3 \%$ \\
\hline Stride Length (m) & $1.01 \pm 0.01$ & $1.01 \pm 0.01$ & $1.8 \%$ & $2.4 \%$ \\
\hline$\%$ of Stance & $1.05 \pm 0.05$ & $1.05 \pm 0.04$ & $7.4 \%$ & $7.7 \%$ \\
\hline$\%$ of Swing & $1.05 \pm 0.04$ & $1.07 \pm 0.05$ & $7.6 \%$ & $10.3 \%$ \\
\hline PVF (\%BW) & $1.05 \pm 0.02$ & $1.04 \pm 0.02$ & $6.2 \%$ & $5.5 \%$ \\
\hline VI (\%BW*s) & $1.09 \pm 0.07$ & $1.06 \pm 0.05$ & $12.8 \%$ & $9.2 \%$ \\
\hline$\%$ of Body Distribution & $1.05 \pm 0.02$ & $1.04 \pm 0.02$ & $6.2 \%$ & $5.5 \%$ \\
\hline
\end{tabular}

limbs for both groups, although the swing time was longer in the hind limbs. This difference influenced the percentages, i.e., the stance percentage was higher and the swing percentage was lower in the forelimbs. In addition, one study suggested that based on the front to hind limb ratio $(1.07 \pm 0.04)$, cats use their forelimbs slightly longer than their hind limbs during the stance phase [11].

The stride length for both the forelimbs and the hind limbs was longer in the male cats and showed a significant correlation to limb length. Thus, the difference is related to the body size of the male cat and not sexrelated. In addition, there was no body mass difference between the groups. As an indicator of body size, the limb length influences the stride length and may influence other variables, such as stance time [28,32]. For small dogs walking on a pressure sensing walkway, most of the temporospatial and kinetic variables were significantly smaller than those of large dogs, and the small dogs had more frequent paw strikes and a shorter gait cycle [18]. The variability could be diminished using dynamic similarity. However, in a study was observed that hind limb PVF in ponies was slightly higher than in horses even though the ponies moved at the same relative velocity [20]

Generally, the vertical force is the maximum force that acts on the body [33]. For both male and female cats,

Table 5 Lengths of the forelimbs and hind limbs $(\mathrm{cm})$ of male and female cats

\begin{tabular}{lcccc}
\hline & Male & & Female & \\
\cline { 2 - 3 } & Mean \pm SD & & Mean \pm SD & \\
\hline Forelimbs & $24.94 \pm 1.94^{\mathbf{a}}$ & & $22.50 \pm 0.83^{\mathbf{b}}$ & 0.012 \\
Hind limbs & $25.61 \pm 2.07^{\mathbf{a}}$ & & $23.33 \pm 0.5^{\mathbf{b}}$ & 0.024 \\
\hline
\end{tabular}

The values that are followed by different letters along each horizontal row are significantly different.
Table 6 Pearson's correlation coefficient between the temporospatial and kinetic values and lengths of the forelimbs and the hind limbs $(\mathrm{cm})$ of male and female cats

\begin{tabular}{lcc}
\hline Variables & Forelimb & Hind limb \\
\hline Stance Time (s) & 0.37 & 0.25 \\
Swing Time (s) & 0.30 & 0.28 \\
Gait cycle time (s) & 0.37 & 0.31 \\
Stride Length (m) & $\mathbf{0 . 6 8 ^ { * }}$ & $\mathbf{0 . 5 7 ^ { * }}$ \\
\% of Stance & 0.21 & -0.006 \\
\% of Swing & -0.25 & -0.11 \\
PVF (\%BW) & -0.18 & 0.15 \\
VI (\%BW*s) & -0.43 & 0.30 \\
\% of Body Distribution & 0.23 & 0.27 \\
\hline
\end{tabular}

*Significant statistical correlation.

the PVF and VI were higher in the forelimbs than the hind limbs. This finding was similar to previously reported data of healthy cats walking on a pressure sensing walkway $[7,9,11]$ or force plate [33]. However, the mean values and proportions differed between the studies and may be associated with the methodologies used for pressure sensing walkway calibration [9] and the system types. Romans et al. [7] cited that differences between the forelimbs and the hind limb ground reaction forces could be less in cats than in dogs, as the mean PVF (\%BW) obtained was 56.41 for the forelimbs and 50.22 for the hind limbs in healthy cats walking on a pressure sensing walkway. In our study, however, the mean PVF (\%BW) values for the forelimbs were $54.95 \pm$ 5.38 and $55.75 \pm 7.66$ in the male and female cats, respectively, and $41.66 \pm 6.46$ and $40.59 \pm 5.21$ for the hind limbs in the male and female cats, respectively. Additionally, in a study of quadruped dynamics, three-fifths of the total vertical force in walking cats was distributed on the forelimbs, and this distribution was associated with a centre-of-gravity location nearer the forelimbs and an impulse produced at the forelimbs [34].

Symmetry changes have been associated with lameness [35,36]; however, the determination of the rate considered normal and that considered abnormal must be determined, as there is no absolute symmetry, which was shown in an analysis of the inverse dynamics gait in dogs [37]. In the present study, the average symmetry rates ranged from 1.01 to 1.09 (asymmetry ranging from 1 to 9\%) which reinforces the importance of bilateral evaluation in gait analysis. Variables such as swing time, swing percentage and impulse showed a maximum percentage of asymmetry greater than $10 \%$, suggesting that these parameters should be interpreted with caution in the detection of asymmetries. Furthermore, the stride length, gait cycle time, the PVF and the body distribution percentage showed the highest degree of symmetry and the 
lowest values for maximum percentage of asymmetry, indicating that these variables seem more appropriate for detecting gait changes.

One of the limitations of the present study was that most tests had powers in the range of 0.1 and a power level of 0.8 is usually necessary to feel that type 2 errors (false negative) are unlikely. Thus, further researches using a larger population of cats are justified.

\section{Conclusions}

The only difference observed between male and female cat was the stride length, which was caused by the larger body size of male cats. This difference did not affect other temporospatial or kinetic variables.

\section{Competing interests}

The authors have declared that no competing interests exist.

\section{Authors' contributions}

MRV, SCR and FSA conceived and designed the study; VMG helped collected the data; MJM performed and interpreted radiology examinations and FOBM helped draft the manuscript; all authors read, contributed to and approved the final manuscript.

\section{Acknowledgements}

We are grateful to FAPESP (The State of São Paulo Research Foundation), CNPq (National Council for Scientific and Technological Development), and CAPES (Coordination for the Improvement of Higher Level Personnel) PROCAD-NF No. 21/2009. We would also like to thank the Universidade Estadual Paulista (UNESP) and the Universidade Federal Rural da Amazônia.

\section{Author details}

'Department of Veterinary Surgery and Anesthesiology, School of Veterinary Medicine and Animal Science - Univ Estadual Paulista (UNESP), Botucatu, SP, Brazil. ${ }^{2}$ Department of Animal Reproduction and Veterinary Radiology, School of Veterinary Medicine and Animal Science - Univ Estadual Paulista (UNESP), Botucatu, SP, Brazil. ${ }^{3}$ Universidade Federal Rural da Amazônia, Instituto de Saúde e Produção Animal, Belém, do Pará, Brazil.

Received: 24 November 2012 Accepted: 24 June 2013

Published: 27 June 2013

\section{References}

1. McLaughlin RM: Kinetic and kinematic gait analysis in dogs. Vet Clin North Am Small Anim Pract 2001, 31:193-201.

2. Budsberg SC, Thomas MW: Advanced diagnostic techniques. In BSVA manual of canine and feline musculoskeletal disorders. Edited by Houlton JEF, Cook JL, Innes JF, Langley-Hobbs SJ. England: British Small Animal Veterinary Association; 2006:27-33.

3. Gillette RL, Angle TC: Recent development in canine locomotor analysis. $A$ review. Vet. J 2008, 178:165-176.

4. Gordon-Evans WJ: Gait analysis. In Veterinary surgery small animal. Edited by Tobias KM, Johnston SA. Canada: Elsevier Saunders; 2012:1190-1196.

5. Pantall A, Gregor RJ, Prilutsky Bl: Stance and swing phase detection during level and slope walking in the cat: effects of slope, injury, subject and kinematic detection method. J Biomech 2012, 45:1529-1533.

6. Voss K, Steffen F: Patient assessment. In Feline orthopedic surgery and musculoskeletal disease. Edited by Montavon PM, Voss K, Langley-Hobbs SJ. Edinburgh: Mosby Elsevier; 2009:3-19.

7. Romans CW, Conzemius MG, Horstman CL, Gordon WJ, Evans RB: Use of pressure platform gait analysis in cats with and without bilateral onychectomy. Am J Vet Res 2004, 65:1276-1278.

8. Romans CW, Gordon WJ, Robinson DA, Evans R, Conzemius MG: Effect of postoperative analgesic protocol on limb function following onychectomy in cats. J Am Vet Med Assoc 2005, 227:89-93.
9. Lascelles BD, Findley K, Correa M, Marcellin-Little D, Roe S: Kinetic evaluation of normal walking and jumping in cats, using a pressure sensitive walkway. Vet Rec 2007, 160:512-516.

10. Carroll G, Narbe R, Peterson K, Kerwin S, Taylor L, Deboer M: A pilot study: sodium urate synovitis as an acute model of inflammatory response using objective and subjective criteria to evaluate arthritic pain in cats. J Vet Pharmacol Therap 2008, 31:456-465.

11. LeQuang T, Maitre P, Colin A, Viguier E: Evaluation spatial-temporal and pressure parameters of normal cats at a walk, using a pressure walkway. In Proceedings of the third international conference on the development of biomedical engineering in Vietnam: 11-14 January 2010. Edited by Magjarevic R. Vietnam: Springer Berlin Heidelberg; 2010:59-61.

12. Guillot M, Moreau M, D'Anjou M-A, Martel-Pelletier J, Pelletier J-P, Troncy E: Evaluation of osteoarthritis in cats: novel information from a pilot study. Vet Surg 2012, 41:328-335.

13. Nunamaker DM, Blauner PD: Normal and abnormal gait. In Textbook of small animal orthopaedics. Edited by Newton CD, Nunamaker DM. Philadelphia: J.B. Lippincott Company; 1985:1083-1095.

14. Clayton HM, Schamhardt HC: Measurement techniques for gait analysis. In Equine locomotion. Edited by Back W, Clayton HM. London: Saunders; 2001:55-76.

15. Besancon MF, Conzemius MG, Derrick TR, Ritter MJ: Comparison of vertical forces in normal greyhounds between force platform and pressure walkway measurement systems. Vet Comp Orthop Traumatol 2003 16:153-157.

16. Lascelles BD, Roe SC, Smith E, Reynolds L, Markham J, Marcellin-Little D, Bergh MS, Budsberg SC: Evaluation of a pressure walkway system for measurement of vertical limb forces in clinically normal dogs. Am J Vet Res 2006, 67:227-282.

17. Light VA, Steiss JE, Montgomery RD, Rumph PF, Wright JC: Temporal-spatial gait analysis by use of a portable walkway system in healthy Labrador retrievers at a walk. Am J Vet Res 2010, 71:997-1002.

18. Kim J, Kazmierczak KA, Breur GJ: Comparison of temporospatial and kinetic variables of walking in small and large dogs on a pressuresensing walkway. Am J Vet Res 2011, 72:1171-1177.

19. Oosterlinck M, Bosmans T, Gasthuys F, Polis I, Van Ryssen B, Dewulf J, Pille F: Accuracy of pressure plate kinetic asymmetry indices and their correlation with visual gait assessment scores in lame and nonlame dogs. Am J Vet Res 2011, 72:820-825.

20. Oosterlinck M, Pille F, Back W, Dewulf J, Gasthuys F: A pressure plate study on fore and hindlimb loading and the association with hoof contact area in sound ponies at the walk and trot. Vet J 2011, 190:71-76.

21. Oosterlinck M, Pille F, Huppes T, Gasthuys F, Bach W: Comparison of pressure plate and force plate gait kinetics in sound warmbloods at walk and trot. Vet J 2010, 186:347-351.

22. Castro M, Soares D, Machado L: Comparison of vertical GRF obtained from force plate, pressure plate and insole pressure system. Port J Sport Sci 2011, 11:849-852

23. DeCamp CE: Kinetic and kinematic gait analysis and the assessment of lameness in the dog. Vet Clin North Am Small Anim Pract 1997, 27:825-840.

24. Fanchon L, Grandjean D: Accuracy of asymmetry indices of ground reaction forces for diagnosis of hind limb lameness in dogs. Am J Vet Res 2007, 68:1089-1094.

25. Horstman CL, Conzemius MG, Evans R, Gordon WJ: Assessing the efficacy of perioperative oral carprofen after cranial cruciate surgery using noinvasive, objective pressure platform gait analysis. Vet Surg 2004, 33:286-292

26. Agostinho FS, Rahal SC, Araújo FAP, Conceição RT, Hussni CA, El-Warrak AO, Monteiro FOB: Gait analysis in clinically healthy sheep from three different age groups using a pressure-sensitive walkway. BMC Vet Res 2012, 8:1-7.

27. Budsberg SC, Verstraete MC, Soutas-Little RW: Force plate analysis of the walking gait in healthy dogs. Am J Vet Res 1987, 48:915-918.

28. Voss K, Wiestner T, Galeandro L, Hässig M, Montavon PM: Effect of dog breed and body conformation on vertical ground reaction forces, impulses, and stance times. Vet Comp Orthop Traumatol 2011, 24:106-112.

29. Cho SH, Park JM, Kwon OY: Gender differences in three dimensional gait analysis data from 98 healthy Korean adults. Clin Biomech 2004, 19:145-152.

30. Patterson KK, Gage WH, Brooks D, Black SE, Mcllroy WE: Evaluation of gait symmetry after stroke: a comparison of current methods and recommendations for standardization. Gait Posture 2010, 31:241-246. 
31. Vilensky JA: Locomotor behavior and control in human and non-human primates: comparisons with cats and dogs. Neurosci Biobehav Rev 1987, 11:263-274.

32. Bertram JEA, Lee DV, Case HN, Todhunter RJ: Comparison of the trotting gaits of Labrador retrievers and greyhounds. Am J Vet Res 2000, 61:832-838.

33. Demes B, Larson SG, Stern JT, Jungers WL, Biknevicius AR, Schmitt D: The kinetics of primate quadrupedalism: "hindlimb drive" reconsidered. J Hum Evol 1994, 26:353-374.

34. Manter JT: The dynamics of quadrupedal walking. J Exp Biol 1938, 15:522-540.

35. Voss K, Imhof J, Kaestner S, Montavon PM: Force plate gait analysis at the walk and trot in dogs with low-grade hindlimb lameness. Vet Comp Orthop Traumatol 2007, 20:299-304.

36. LeQuang T, Maitre P, Roger T, Viguier E: Is a pressure walkway system able to highlight a lameness in dog? J Anim Vet Adv 2009, 8:1936-1944.

37. Colborne GR: Are sound dogs mechanically symmetric at trot? No, actually. Vet Comp Orthop Traumatol 2008, 21:294-301.

doi:10.1186/1746-6148-9-129

Cite this article as: Verdugo et al:: Kinetic and temporospatial parameters in male and female cats walking over a pressure sensing walkway. BMC Veterinary Research 2013 9:129.

\section{Submit your next manuscript to BioMed Central and take full advantage of:}

- Convenient online submission

- Thorough peer review

- No space constraints or color figure charges

- Immediate publication on acceptance

- Inclusion in PubMed, CAS, Scopus and Google Scholar

- Research which is freely available for redistribution 